\title{
Determination of Four Residues of Fluoroquinolones with Similar Structure in Fish by Modified QuEChERS Protocol Coupled to Capillary Electrophoresis (CE) with End-Column Electrochemiluminescence (ECL)
}

\author{
Wenjuan Zhang ${ }^{1}$, Fuxiu Yang ${ }^{1}$, Hong Wang ${ }^{1}$, Chunxiu $G u^{1,2, *}$, Kaowen Zhou ${ }^{1,2, *}$ \\ ${ }^{1}$ Biochemical Engineering College, Beijing Union University, Beijing 100023, China \\ ${ }^{2}$ Beijing Key Laboratory of Biomass Waste Resource Utilization, Beijing 100023, China \\ *E-mail: zhoukaowen@buu.edu.cn, guchunxiu@ buu.edu.cn
}

doi: $10.20964 / 2020.07 .55$

Received: 2 March 2020/ Accepted: 23 April 2020 / Published: 10 June 2020

\begin{abstract}
A new method was established for simultaneousyl determining ciprofloxacin (CIP), enrofloxacin (ENR), norfloxacin (NOR) and pefloxacin (PEF) in fish by capillary electrophoresis (CE) coupled with end-column electrochemiluminescence (ECL) with modified QuEChERS. The structural differences of $4 \mathrm{FQs}$ are too small to separate them by conventional CE. However, their separation efficiency can be improved by adjusting the composition of separation buffer. The parameters about ECL analysis and CE separation were investigated in detail. The use of methanol and sodium sulfate in QuEChERS can improve the pretreatment effect of the sample. The optimum experimental conditions include analysis conditions (detection potential $1.20 \mathrm{~V}$ vs. $\mathrm{Ag} / \mathrm{AgCl}, \mathrm{Ru}(\mathrm{bpy}) 3^{2+}$ concentration $6 \mathrm{mmol} / \mathrm{L}$, phosphate buffer solution concentration $40 \mathrm{mmol} / \mathrm{L}$ and $\mathrm{pH} 7.0$ in ECL detection cell), separation conditions (separation voltage $13.0 \mathrm{kV}, 17.5 \%$ cyclodextrin solution (v/v) as additive, phosphate buffer solution concentration $20 \mathrm{mmol} / \mathrm{L}$ and $\mathrm{pH} 5.0$ in capillary), and sample conditions (injection time $7 \mathrm{~s}$ and injection voltage $12.0 \mathrm{kV}$ ). The limits of detection $(3 \sigma)$ of this method were $8.8 \times 10^{-5} \mathrm{mg} / \mathrm{mL}$ for CIP, $3.5 \times 10^{-6} \mathrm{mg} / \mathrm{mL}$ for ENR, $7.5 \times 10^{-5} \mathrm{mg} / \mathrm{mL}$ for NOR and $2.7 \times 10^{-6} \mathrm{mg} / \mathrm{mL}$ for PEF. The relative standard deviations (RSD) were less than $2.6 \%$ for ECL intensity and less than $2.3 \%$ for migration time. This method was successfully utilized to simultaneously determine CIP, ENR, NOR and PEF in fish.
\end{abstract}

Keywords: Fluoroquinolones; Residue; Fish; CE-ECL; QuEChERS

\section{$\underline{\text { FULL TEXT }}$}

(C) 2020 The Authors. Published by ESG (www.electrochemsci.org). This article is an open access article distributed under the terms and conditions of the Creative Commons Attribution license (http://creativecommons.org/licenses/by/4.0/). 